Committee on Exchange of Personnel to include exchanges between AALL librarians and law librarians from any other country. Until this change the Special Committee on Exchange of Personnel was addressing itself only to exchanges between AALL members and members of the British and Irish Association of Law Librarians. The broadened scope of the committee came about as a result of inquiries from law librarians outside the United Kingdom, as well as inquiries from AALL members interested in exchanging positions in countries other than in the United Kingdom.

Any law librarian interested in exchanging positions with AALL members for periods of 1 month to 1 year should send inquiries to $O$. James Werner, San Diego County Law Library, 1105 Front Street, San Diego, CA 92101, USA.

\title{
INVESTIGATION OF LAW REPORTING IN CANADA
}

At the request of a committee of the Canadian Deputy AttorneysGeneral, a survey of official and commercial law reporting services has been undertaken by the Canadian Law Information Council, a special nation-wide organization. The survey is proceeding in three phases: a statistical study, an historical and bibliographic study, and an examination of the quality of law reports.

In an interim progress report (published in the National, July-August 1980, p. 9) the Canadian Law Information Council comments about the duplication, comprehensiveness, and prices of Canadian law reports. It is reported here in part as the subjects are of interest to lawyers and law libraries throughout the world:

\section{Duplication}

The Canadian law reporting scheme suffers from incomplete reporting of some cases, duplicate reporting of others and dispersion of cases in a large number of series.

The incidence of duplication rests at 51 per cent of all cases reported.

Approximately 16 per cent of all cases in Canada are incompletely reported in the sense that they do not appear in certain critical types of reporters. Cases which appear only in topical reporters without being pre-digested or published in provincial series are examples of incomplete reporting.

Complicating the picture of law reporting in Canada is the fact of dispersion. Those judgements which are not duplicated are scattered among a large number of different reporters. The effect of this is that comprehensive access to case law requires consulting many law reports. 
Furthermore, those who must purchase comprehensive access (e.g. libraries) are faced with a formidable and ever increasing cost burden. Nowhere is the problem of dispersion more obvious than in the province of Alberta which is served by two national as well as its own predigest service, two provincial reporters, and two multi-jurisdictional reporters. A center core of judgments appears in all sources and the remainder are widely scattered.

\section{Comprehensiveness}

Investigation of comprehensiveness attempted to assess the problem of unreported judgments in Canadian courts and to document specific gaps in coverage. Tentative conclusion is that the problem of unreported cases is not nearly as great as it once was because of pre-digest services but that gaps in coverage exist for lower courts, administrative tribunals, the Atlantic Provinces and the Territories.

How effective are the pre-digests? The All Canada Weekly Summaries and Weekly Criminal Bulletin, for example, digest about 85 per cent of all available decisions. Were it not for their weak coverage of the Atlantic Provinces their comprehensiveness would approach 90 per cent.

Multi-jurisdictional reporters like the Western Weekly Reports and Dominion Law Reports publish about 15 per cent of the available decisions from each jurisdiction. These services illustrate a high degree of selectivity rather than comprehensiveness.

Provincial reporters average 65 per cent comprehensiveness except in Ontario and British Columbia where the total number of judgments is high. They average 15 per cent and 18 per cent respectively.

Among criminal reporters Canadian Criminal Cases are more comprehensive than Criminal Reports, publishing approximately three times as many judgments.

\section{Price}

Annual subscription prices to individual law reporters rose an average of 75 per cent in the $1974-78$ period. Further, the annual cost of maintaining a comprehensive library of major law reporters in 1974 was $\$ 2,100$, but by 1978, with the appearance of many new series, this figure had risen to $\$ 5,000$ and is undoubtedly climbing still.

Rising prices are not new to consumers; however, it is interesting to note whether appreciable benefits to users have been the result of any of these increases. The Western Weekly Reports showed a marked improvement in timeliness for its 55 per cent increase during the period under study. Maritime Law Book's subscription prices rose by 93 per cent but they also provided consumers with 86 per cent more content.

(Based on a report in the National, July-August 1980.) 